Journal of Mathematics and Statistics 5 (4): 305-310, 2009

ISSN 1549-3644

(C) 2009 Science Publications

\title{
Cost Analysis of a System Involving Common-Cause Failures and Preventive Maintenance
}

\author{
M.Y. Haggag \\ Department of Mathematics and Statistics, \\ Faculty of Science, Al-Azhar University, Cairo, Egypt
}

\begin{abstract}
Problem statement: Many authors have studied the cost analysis of a two-unit cold standby redundant system with two types of unit failure, but no attention was paid to the reliability of a system involving common-cause failures and preventive maintenance. Question was raised whether the preventive maintenance would be effective on the reliability and performance of the system. Determine the efficacy of preventive maintenance on the reliability and performance of the system. Approach: In this study, the Mean Time to System Failure (MTSF), steady state availability and the profit function of a two-unit cold standby repairable redundant system involving common-cause failures and preventive maintenance were discussed. We analyzed the system by using Kolmogorov's forward equations method. Some particular cases have also been discussed graphically. Results: The results indicated that the system with preventive maintenance is better than the system without preventive maintenance. Conclusion: These results indicated that the better maintenance of parts of the system originated better reliability and performance of the system.
\end{abstract}

Key words: Cost analysis, Mean Time to System Failure (MTSF), steady-state availability, busy period, profit function, preventive maintenance, Kolmogorov's forward equations method

\section{INTRODUCTION}

In various reliability systems we often come to maximize the profit. The profit of a system depends on cost incurred. The redundancy allocation problem has been studied for many different system structure. In a standby redundant system, some additional paths are created for the proper functioning of the system. The standby unit support increases the reliability of the system. On the failure of the operating unit, a standby unit is switched on by perfect or imperfect switching device. Also, the better maintenance of parts of the system originates better reliability and performance of the system. Maintainability is defined as the probability that a failed system will restored to a functioning state with a given period of time.

Thus introducing redundant parts and providing maintenance and repair may achieve high degree of reliability. Earlier researchers ${ }^{[1-3]}$ have studied the cost analysis of two unit redundant systems with two types of repair. The researchers ${ }^{[4-6]}$ have studied the cost analysis of different systems ${ }^{[7]}$. Evaluate reliability and availability of two different systems by using linear first order differential equations.

The purpose of this study is to study the cost analysis of a two-unit cold standby redundant system with two types of unit failure involving common cause failure and preventive maintenance. Several reliability characteristics are obtained by using Kolmogorov's forward equations.

Initially one unit is operative and the other is kept as cold standby. Each unit works in two different types of failures. The system fails when both units fail totally. The failure and repair times are assumed to have exponential distribution. The availability, Mean Time to System Failure (MTSF) and cost function are studied. Some particular cases study the effect of preventive maintenance on the system performance are shown.

The following system characteristics are obtained:

- Mean Time to System Failure (MTSF) with and without preventive maintenance

- Steady state availability with and without preventive maintenance

- Busy period, expected frequency of preventive maintenance

- Cost analysis with and without preventive maintenance

\section{Assumptions:}

- The system consists of two similar units, one is main and the other is its standby 
- Initially one unit is operative and the other unit is kept as cold standby

- A perfect switch is used to switch-on standby unit and switch-over time is negligible

- The system has three states: Good, failed and under preventive maintenance

- Both units suffer two types of hardware failures and common-cause failures

- Unit failure, common-cause failure and repair rates are constants

- Failure rates and repair rates follow exponential distribution

- The system is down when both units are nonoperative

- The system can reach a failed states $S_{3}, S_{4}, S_{5}, S_{6}$, due to unit failure for its two units

- Common-cause failure bring the system directly from good states $S_{0}$ to failed state $S_{8}$

Formulation of Mathematical Model: By employing the method of linear first order differential equations For Fig. 1 and by using the above-mentioned set of assumptions, we can obtain the following differential equations:

$\mathrm{P}_{0}^{\prime}(\mathrm{t})=-\left(\propto_{1}+\propto_{2}+\gamma+\lambda\right) \mathrm{P}_{0}(\mathrm{t})+\beta_{1} \mathrm{P}_{1}(\mathrm{t})+\beta_{2} \mathrm{P}_{2}(\mathrm{t}) \delta \mathrm{P}_{7}(\mathrm{t})+\eta \mathrm{P}_{8}(\mathrm{t})$

$\mathrm{P}^{\prime}{ }_{1}(\mathrm{t})=-\left(\propto_{1}+\propto_{2}+\beta_{1}\right) \mathrm{P}_{1}(\mathrm{t})+\alpha_{1} \mathrm{P}_{0}(\mathrm{t})+\beta_{2} \mathrm{P}_{3}(\mathrm{t})+\beta_{1} \mathrm{P}_{5}(\mathrm{t})$

$\mathrm{P}_{2}^{\prime}(\mathrm{t})=-\left(\propto_{1}+\alpha_{2}+\beta_{2}\right) \mathrm{P}_{2}(\mathrm{t})+\alpha_{2} \mathrm{P}_{0}(\mathrm{t})+\beta_{1} \mathrm{P}_{4}(\mathrm{t})+\beta_{2} \mathrm{P}_{6}(\mathrm{t})$

$\mathrm{P}_{3}^{\prime}(\mathrm{t})=-\left(\beta_{2} \mathrm{P}_{3}(\mathrm{t})+\alpha_{2} \mathrm{P}_{1}(\mathrm{t})\right.$

$\mathrm{P}_{4}^{\prime}(\mathrm{t})=-\left(\beta_{1} \mathrm{P}_{4}(\mathrm{t})+\alpha_{1} \mathrm{P}_{2}(\mathrm{t})\right.$

$\mathrm{P}_{5}^{\prime}(\mathrm{t})=-\left(\beta_{1} \mathrm{P}_{5}(\mathrm{t})+\alpha_{1} \mathrm{P}_{1}(\mathrm{t})\right.$

$\mathrm{P}_{6}^{\prime}(\mathrm{t})=-\left(\beta_{2} \mathrm{P}_{6}(\mathrm{t})+\alpha_{2} \mathrm{P}_{2}(\mathrm{t})\right.$

$\mathrm{P}^{\prime}{ }_{7}(\mathrm{t})=-\delta \mathrm{P}_{7}(\mathrm{t})+\lambda \mathrm{P}_{0}(\mathrm{t})$

$\mathrm{P}_{8}^{\prime}(\mathrm{t})=-\eta \mathrm{P}_{8}(\mathrm{t})+\eta \mathrm{P}_{\mathrm{o}}(\mathrm{t})$
Initial conditions: If we let $\mathrm{P}(\mathrm{t})$ denote the probability row vector at time $t$, the initial conditions for this problem are:

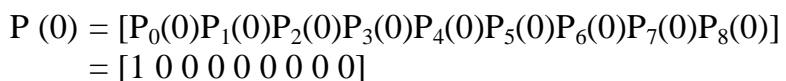

We can put the above system of differential equations in the matrix form as:

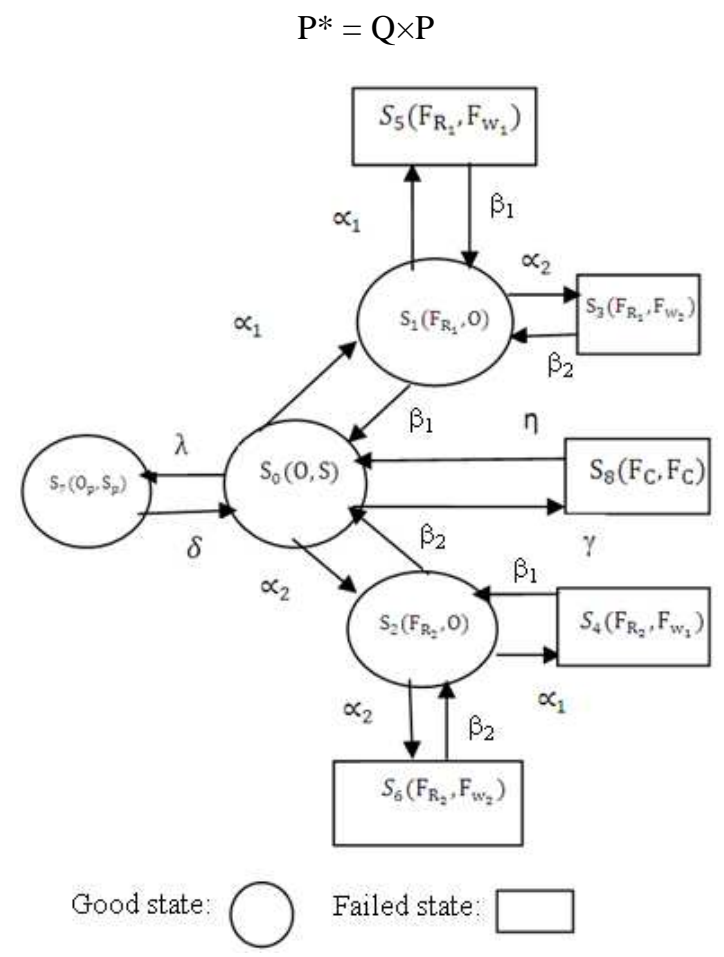

Fig. 1: State of the system

Where:

$\mathrm{Q}=\left[\begin{array}{ccccccccc}-\left(\propto_{1}+\propto_{2}+\gamma+\lambda\right) & \beta_{1} & \beta_{2} & 0 & 0 & 0 & 0 & \delta & \eta \\ \alpha_{1} & -\left(\propto_{1}+\propto_{2}+\beta_{1}\right) & 0 & \beta_{2} & 0 & \beta_{1} & 0 & 0 & 0 \\ \alpha_{2} & 0 & -\left(\propto_{1}+\propto_{2}+\beta_{2}\right) & 0 & \beta_{1} & 0 & \beta_{2} & 0 & 0 \\ 0 & \alpha_{2} & 0 & -\beta_{3} & 0 & 0 & 0 & 0 & 0 \\ 0 & 0 & \alpha_{1} & 0 & -\beta_{1} & 0 & 0 & 0 & 0 \\ 0 & \propto_{1} & 0 & 0 & 0 & -\beta_{1} & 0 & 0 & 0 \\ 0 & 0 & \alpha_{2} & 0 & 0 & 0 & -\beta_{2} & 0 & 0 \\ \lambda & 0 & 0 & 0 & 0 & 0 & 0 & -\delta & 0 \\ \gamma & 0 & 0 & 0 & 0 & 0 & 0 & 0 & -\eta\end{array}\right]$

Mean Time to System Failure (MTSF): To calculate the MTSF we take the transpose matrix of Q and delete the rows and columns for the absorbing state, the new matrix is called A. the expected time to reach an absorbing state is calculated from: 
$\mathrm{MTTF}=\mathrm{P}(0)\left(-\mathrm{A}^{-1}\right)\left\lfloor\begin{array}{l}1 \\ 1 \\ 1 \\ 1\end{array}\right\rfloor$

Where:

$$
\mathrm{A}=\left[\begin{array}{cccc}
-\left(\propto_{2}+\propto_{2}+\gamma+\lambda\right) & \alpha_{2} & \alpha_{2} & \lambda \\
\beta_{1} & -\left(\propto_{1}+\propto_{2}+\beta_{2}\right) & 0 & 0 \\
\beta_{2} & 0 & -\left(\propto_{1}+\propto_{2}+\beta_{2}\right) & 0 \\
\delta & 0 & 0 & -\delta
\end{array}\right]
$$

The steady state mean Time to System Failure (MTSF) is given by:

$$
\begin{aligned}
\text { MTSF }= & \left(\left(\left(\alpha_{1}+\alpha_{2}\right)^{2}(\lambda+2 \delta)+\lambda\left[\left(\alpha_{1}+\alpha_{2}\right)\left(\beta_{1}+\beta_{2}\right)+\beta_{1} \beta_{2}\right]+\delta\left[\alpha_{1}+\left(\beta_{1}+2 \beta_{2}\right)+\alpha_{2}\left(2 \beta_{1}+\beta_{2}\right)+\beta_{1} \beta_{2}\right]\right) /\left(\delta \left\{\left(\alpha_{1}+\alpha_{2}\right)\right.\right.\right. \\
& {\left.\left.\left.\left[\left(\alpha_{1}+\alpha_{2}\right)^{2}+\left(\alpha_{1} \beta_{2}+\alpha_{2} \beta_{1}\right)\right]+\gamma\left[\left(\alpha_{1}+\alpha_{2}\right)\left(\beta_{1}+\beta_{2}\right)+\beta_{1} \beta_{2}\right]\right\}\right)\right) }
\end{aligned}
$$

Availability analysis: The initial conditions for this problem are the same as for the reliability case:

$\mathrm{P}(0)=[1,0,0,0,0,0,0,0,0]$

the differential equations form can be expressed as:

$$
\left[\begin{array}{l}
\mathrm{P}_{0}^{*} \\
\mathrm{P}_{1}^{*} \\
\mathrm{P}_{2}^{*} \\
\mathrm{P}_{3}^{*} \\
\mathrm{P}_{4}^{*} \\
\mathrm{P}_{5}^{*} \\
\mathrm{P}_{6}^{*} \\
\mathrm{P}_{7}^{*} \\
\mathrm{P}_{8}^{*}
\end{array}\right]=\left[\begin{array}{ccccccccc}
-\left(\propto_{1}+\alpha_{2}+\gamma+\lambda\right) & \beta_{1} & \beta_{2} & 0 & 0 & 0 & 0 & \delta & \eta \\
\alpha_{1} & -\left(\propto_{1}+\alpha_{2}+\beta_{1}\right) & 0 & \beta_{2} & 0 & \beta_{1} & 0 & 0 & 0 \\
\alpha_{2} & 0 & -\left(\propto_{1}+\alpha_{2}+\beta_{2}\right) & 0 & \beta_{1} & 0 & \beta_{2} & 0 & 0 \\
0 & \alpha_{2} & 0 & -\beta_{3} & 0 & 0 & 0 & 0 & 0 \\
0 & 0 & \alpha_{1} & 0 & -\beta_{1} & 0 & 0 & 0 & 0 \\
0 & \propto_{1} & 0 & 0 & 0 & -\beta_{1} & 0 & 0 & 0 \\
0 & 0 & \alpha_{2} & 0 & 0 & 0 & -\beta_{2} & 0 & 0 \\
\lambda & 0 & 0 & 0 & 0 & 0 & 0 & -\delta & \\
\gamma & 0 & 0 & 0 & 0 & 0 & 0 & 0 & -\eta
\end{array}\right]\left[\begin{array}{l}
\mathrm{P}_{0} \\
\mathrm{P}_{1} \\
\mathrm{P}_{2} \\
\mathrm{P}_{3} \\
\mathrm{P}_{4} \\
\mathrm{P}_{5} \\
\mathrm{P}_{6} \\
\mathrm{P}_{7} \\
\mathrm{P}_{8}
\end{array}\right]
$$

In the steady state, the derivatives of the state probabilities become zero, i.e.:

$\mathrm{QP}(\infty)=0$

Then the steady state probabilities can be calculated as follows:

$\mathrm{A}(\infty)=\mathrm{P}_{0}(\infty)+\mathrm{P}_{1}(\infty)+\mathrm{P}_{2}(\infty)+\mathrm{P}_{7}(\infty)$

Then the matrix form became:

$$
\left[\begin{array}{ccccccccc}
-\left(\alpha_{1}+\alpha_{2}+\gamma+\lambda\right) & \beta_{1} & \beta_{2} & 0 & 0 & 0 & 0 & \delta & \eta \\
\alpha_{1} & -\left(\propto_{1}+\alpha_{2}+\beta_{1}\right) & 0 & \beta_{2} & 0 & \beta_{1} & 0 & 0 & 0 \\
\alpha_{2} & 0 & -\left(\alpha_{1}+\alpha_{2}+\beta_{2}\right) & 0 & \beta_{1} & 0 & \beta_{2} & 0 & 0 \\
0 & \alpha_{2} & 0 & -\beta_{3} & 0 & 0 & 0 & 0 & 0 \\
0 & 0 & \alpha_{1} & 0 & -\beta_{1} & 0 & 0 & 0 & 0 \\
0 & \alpha_{1} & 0 & 0 & 0 & -\beta_{1} & 0 & 0 & 0 \\
0 & 0 & \alpha_{2} & 0 & 0 & 0 & -\beta_{2} & 0 & 0 \\
\lambda & 0 & 0 & 0 & 0 & 0 & 0 & -\delta & \\
\gamma & 0 & 0 & 0 & 0 & 0 & 0 & 0 & -\eta
\end{array}\right]\left[\begin{array}{l}
P_{0} \\
P_{1} \\
P_{2} \\
P_{3} \\
P_{4} \\
P_{5} \\
P_{6} \\
P_{7} \\
P_{8}
\end{array}\right]=\left[\begin{array}{l}
0 \\
0 \\
0 \\
0 \\
0 \\
0 \\
0 \\
0 \\
0
\end{array}\right]
$$


To obtain $\mathrm{P}_{0}(\infty)+\mathrm{P}_{1}(\infty)+\mathrm{P}_{2}(\infty)+\mathrm{P}_{7}(\infty)$ we solve the Eq. 4 by using following normalizing condition:

$\mathrm{P}_{0}(\infty)+\mathrm{P}_{1}(\infty)+\mathrm{P}_{2}(\infty)+\mathrm{P}_{1}(\infty)+\mathrm{P}_{2}(\infty)+\mathrm{P}_{1}(\infty)+\mathrm{P}_{2}(\infty)+\mathrm{P}_{7}(\infty)+\mathrm{P}_{8}(\infty)=1$

We substitute the Eq. 6 in any one of the redundant rows in Eq. 4 yield:

$$
\left[\begin{array}{ccccccccc}
-\left(\propto_{1}+\alpha_{2}+\gamma+\lambda\right) & \beta_{1} & \beta_{2} & 0 & 0 & 0 & 0 & \delta & \eta \\
\alpha_{1} & -\left(\propto_{1}+\alpha_{2}+\beta_{1}\right) & 0 & \beta_{2} & 0 & \beta_{1} & 0 & 0 & 0 \\
\alpha_{2} & 0 & -\left(\alpha_{1}+\alpha_{2}+\beta_{2}\right) & 0 & \beta_{1} & 0 & \beta_{2} & 0 & 0 \\
0 & \alpha_{2} & 0 & -\beta_{3} & 0 & 0 & 0 & 0 & 0 \\
0 & 0 & \alpha_{1} & 0 & -\beta_{1} & 0 & 0 & 0 & 0 \\
0 & \propto_{1} & 0 & 0 & 0 & -\beta_{1} & 0 & 0 & 0 \\
0 & 0 & \alpha_{2} & 0 & 0 & 0 & -\beta_{2} & 0 & 0 \\
\lambda & 0 & 0 & 0 & 0 & 0 & 0 & -\delta & \\
1 & 1 & 1 & 1 & 1 & 1 & 1 & 1 & 1
\end{array}\right]\left[\begin{array}{l}
\mathrm{P}_{0} \\
\mathrm{P}_{1} \\
\mathrm{P}_{2} \\
\mathrm{P}_{3} \\
\mathrm{P}_{4} \\
\mathrm{P}_{5} \\
\mathrm{P}_{6} \\
\mathrm{P}_{7} \\
\mathrm{P}_{8}
\end{array}\right]=\left[\begin{array}{l}
0 \\
0 \\
0 \\
0 \\
0 \\
0 \\
0 \\
0 \\
0 \\
0
\end{array}\right.
$$

The steady state availability $\mathrm{A}(\infty)$ is given by:

$\mathrm{A}(\infty)=\beta_{2} \beta_{1} \eta\left[\beta_{1} \beta_{2}(\lambda+\delta)+\delta\left(\alpha_{1} \beta_{2}+\alpha_{2} \beta_{1}\right)\right] / \mathrm{D}$

Where:

$$
\mathrm{D}=\beta_{1}^{2} \beta_{2}^{2}(\gamma \delta+\lambda \eta+\delta \eta)+\eta \delta\left(\alpha_{1} \beta_{2}+\alpha_{2} \beta_{1}\right)\left(\alpha_{1} \beta_{2+} \alpha_{2} \beta_{1}+\beta_{1} \beta_{2}\right)
$$

Busy period analysis: The initial conditions for this problem are the same as for the reliability case: The differential equations form can be expressed as availability case.

Then the steady state busy period $\mathrm{B}(\infty)$ is given by:

$\mathrm{B}(\infty)=1-\left(\mathrm{P}_{0}(\infty)+\mathrm{P}_{7}(\infty)\right)=\left(1-\beta_{2}{ }^{2} \beta_{1}^{2} \eta(\lambda+\delta)\right) / \mathrm{D}$

The expected frequency of preventive maintenance: The initial conditions for this problem are the same as for the reliability case. Then the steady state, the expected frequency of preventive maintenance per unit time $K(\infty)$ is given by:

$\mathrm{K}(\infty)=\mathrm{P}_{7}(\infty)=\lambda \eta \beta_{1}{ }^{2} \beta_{2}{ }^{2} / \mathrm{D}$

Cost analysis: The expected total profit per unit time incurred to the system in the steady-state is given by:

$$
\begin{aligned}
& \text { Profit = total revenue-total cost } \\
& \mathrm{PF}=\mathrm{RA}(\infty)-\mathrm{C}_{1} \mathrm{~B}(\infty)-\mathrm{C}_{2} \mathrm{~K}(\infty)
\end{aligned}
$$

Where:

$\mathrm{PF}=$ The profit incurred to the system

$\mathrm{R}=$ The revenue per unit up-time of the system

$\mathrm{C}_{1}=$ The cost per unit time which the system is under repair

$\mathrm{C}_{2}=$ The cost per preventive maintenance
From Eq. 7-9, the expected total profit per unit time incurred to the system in the steady-state is given by:

$$
\begin{aligned}
\mathrm{PF}= & \left(\left(\mathrm{R}\left(\beta_{2} \beta_{1} \eta\left(\beta_{1} \beta_{2}(\lambda+\delta)+\delta\left(\alpha_{1} \beta_{2}+\alpha_{2} \beta_{1}\right)\right)\right)\right.\right. \\
& \left.\left.-\mathrm{C}_{1}\left(\mathrm{D}-\beta_{2}{ }^{2} \beta_{1}^{2} \eta(\lambda+\delta)\right)-\mathrm{C}_{2} \lambda \eta\left(\beta_{2}\right)^{2}\left(\beta_{1}\right)^{2}\right)\right) \\
& /\left(\beta_{2}{ }^{2} \beta_{1}{ }^{2}(\gamma \delta+\lambda \eta+\delta \eta)+\eta \delta\left(\alpha_{1} \beta_{2}+\alpha_{2} \beta_{1}\right)\right. \\
& \left.\left.\left(\alpha_{1} \beta_{2}+\alpha_{2} \beta_{1}+\beta_{1} \beta_{2}\right)\right)\right)
\end{aligned}
$$

Special case: When the preventive maintenance is not available.

The mean time to system failure is given by:

$$
\begin{aligned}
\operatorname{MTSF}= & \left(\left(\left(\beta_{1}\left(\alpha_{1}+2 \alpha_{2}\right)+\beta_{2}\left(2 \alpha_{1}+\alpha_{2}\right)+\beta_{1} \beta_{2}\right.\right.\right. \\
& \left.\left.+2\left(\alpha_{1}+\alpha_{2}\right)^{2}\right)\right) /\left(( \alpha _ { 1 } + \alpha _ { 2 } ) \left[\left(\alpha_{1}+\alpha_{2}\right)^{2}\right.\right. \\
& \left.\left.\left.+\left(\alpha_{1} \beta_{2}+\alpha_{2} \beta_{1}\right)\right]+\gamma\left[\left(\alpha_{1}+\alpha_{2}\right)\left(\beta_{1}+\beta_{2}\right)+\beta_{1} \beta_{2}\right]\right)\right)
\end{aligned}
$$
by:

The steady state availability of the system is given

$\mathrm{A}(\infty)=\left(\left(\beta_{2} \beta_{1} \eta\left(\alpha_{1} \beta_{2}+\alpha_{2} \beta_{1}+\beta_{1} \beta_{2}\right)\right) / \mathrm{D}_{1}\right.$

Where:

$$
D_{1}=\beta_{2}^{2} \beta_{1}^{2}(\gamma+\eta)+\eta \delta\left(\alpha_{1} \beta_{2}+\alpha_{2} \beta_{1}\right)\left(\alpha_{1} \beta_{2}+\alpha_{2} \beta_{1}+\alpha_{1} \beta_{2}\right)
$$
by:

The steady state busy period of the system is given

$$
\mathrm{B}(\infty)=\left(1-\beta_{2}^{2} \beta_{1}^{2} \eta\right) / \mathrm{D}_{1}
$$

The expected total profit incurred to the system in the steady-state is given by:

$\mathrm{PF}=\mathrm{RA}(\infty)-\mathrm{C}_{1} \mathrm{~B}(\infty)$ 


$$
\begin{aligned}
\mathrm{PF}= & \left(\left(\mathrm{R}\left(\beta_{2} \beta_{1} \eta\left(\beta_{1} \beta_{2}+\left(\alpha_{1} \beta_{2}+\alpha_{2} \beta_{1}\right)\right)\right)\right.\right. \\
& \left.-C_{1}\left(D_{1}-\beta_{2}^{2} \beta_{1}^{2} \eta\right)\right) /\left(\left(\beta_{2}^{2} \beta_{1}^{2}+(\gamma+\eta)\right.\right. \\
& \left.\left.\left.+\eta\left(\alpha_{1} \beta_{2}+\alpha_{2} \beta_{1}\right)\left(\alpha_{1} \beta_{2}+\alpha_{2} \beta_{1}+\beta_{1} \beta_{2}\right)\right)\right)\right) D_{1}
\end{aligned}
$$

\section{MATERIALS AND METHODS}

Many researchers have studied the cost analysis of a two-unit cold standby redundant system with two types of unit failure without common-cause failures and preventive maintenance. In this study, the Mean Time to System Failure (MTSF), the steady-state availability, the steady state busy period and profit function of the system are obtained for both systems with and without preventive maintenance.

We analyze the system by using Kolmogorov's forward equations method. Next, some numerical computations are computed to show the effect of preventive maintenance on the system.

\section{RESULTS}

If we put: $\alpha_{2}=0.04, \beta_{1}=0.05, \beta_{2}=0.06, \lambda=0.02$, $\delta=0.02, \gamma=0.001, \eta=0.04$ in Eq. $3,7,10-12$ and 14 we get the following:

- Table 1: Show relation between failure rate of type I and the MTSF of the system (with and without PM)

- Table 2: Show relation between failure rate of type 1 and availability of the system (with and without PM)

Table 1: Relation between failure rate of type 1 and the MTSF (with and without PM)

\begin{tabular}{lll}
\hline $\begin{array}{l}\text { MTSF of the system } \\
\text { without PM }\end{array}$ & $\begin{array}{l}\text { MTSF of the system } \\
\text { with PM }\end{array}$ & $\alpha_{1}$ \\
\hline 75.901 & 102.85 & 0.01 \\
47.893 & 79.502 & 0.02 \\
39.213 & 64.386 & 0.03 \\
33.113 & 53.894 & 0.04 \\
28.610 & 46.229 & 0.05 \\
25.159 & 40.407 & 0.06 \\
22.435 & 35.846 & 0.07 \\
20.233 & 32.185 & 0.08 \\
18.418 & 29.185 & 0.09 \\
16.897 & 26.685 & 0.10
\end{tabular}

Table 2: Relation between failure rate of type 1 and availability (with and without PM)

\begin{tabular}{lll}
\hline $\begin{array}{l}\text { Availability of the system } \\
\text { without PM }\end{array}$ & $\begin{array}{l}\text { Availability of the system } \\
\text { with PM }\end{array}$ & $\alpha_{1}$ \\
\hline 0.70633 & 0.78695 & 0.01 \\
0.63994 & 0.72508 & 0.02 \\
0.58178 & 0.66720 & 0.03 \\
0.53129 & 0.61435 & 0.04 \\
0.48756 & 0.56677 & 0.05 \\
0.44959 & 0.52421 & 0.06 \\
0.41651 & 0.48628 & 0.07 \\
0.38753 & 0.45248 & 0.08 \\
0.36201 & 0.42234 & 0.09 \\
0.33942 & 0.39539 & 0.10 \\
\hline
\end{tabular}

- Table 3: Show relation between failure rate of type 1 and the profit of the system (with and without PM)

- Fig. 2: Show relation between the failure rate of type 1 and the MTSF

- Fig. 3: Show relation between the failure rate of type 1 and the availability

- Fig. 4: Show relation between the failure rate of type 1 and expected total profit

Table 3: Relation between failure rate of type 1 and the profit (with and without PM)

\begin{tabular}{lll}
\hline $\begin{array}{l}\text { The profit of the system } \\
\text { without PM }\end{array}$ & $\begin{array}{l}\text { The profit of the system } \\
\text { with PM }\end{array}$ & $\alpha_{1}$ \\
\hline 644.17 & 728.12 & 0.01 \\
570.91 & 660.54 & 0.02 \\
507.44 & 597.83 & 0.03 \\
452.83 & 540.94 & 0.04 \\
405.84 & 489.95 & 0.05 \\
365.28 & 444.55 & 0.06 \\
330.09 & 404.22 & 0.07 \\
299.39 & 368.39 & 0.08 \\
272.45 & 336.52 & 0.09 \\
248.68 & 308.10 & 0.10 \\
\hline
\end{tabular}

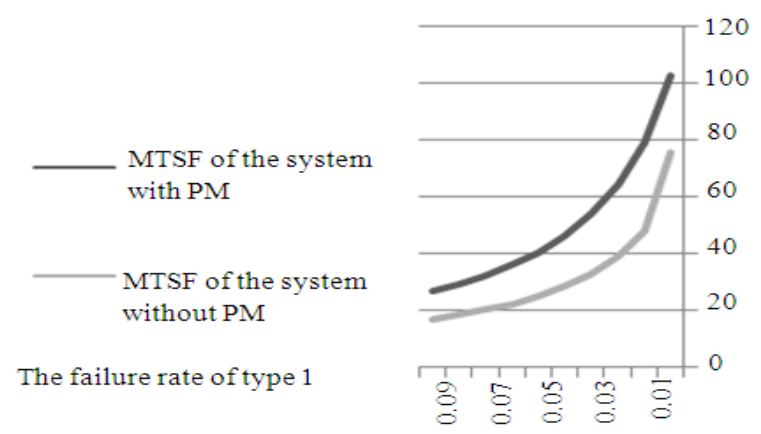

Fig. 2: Relation between the failure rate of type 1 and the MTSF

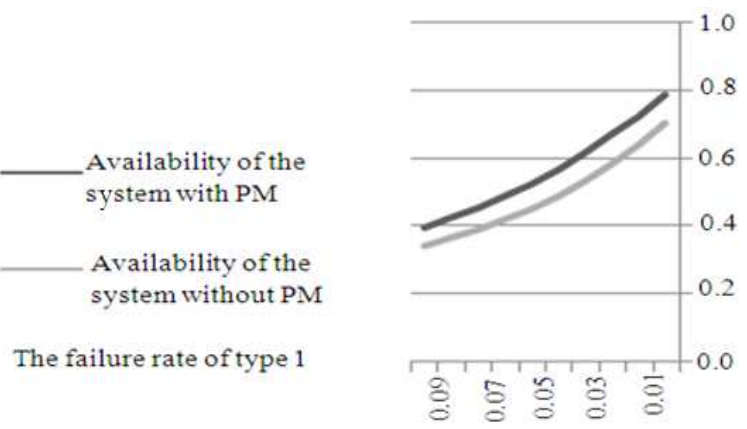

Fig. 3: Relation between the failure rate of type 1 and the profit 


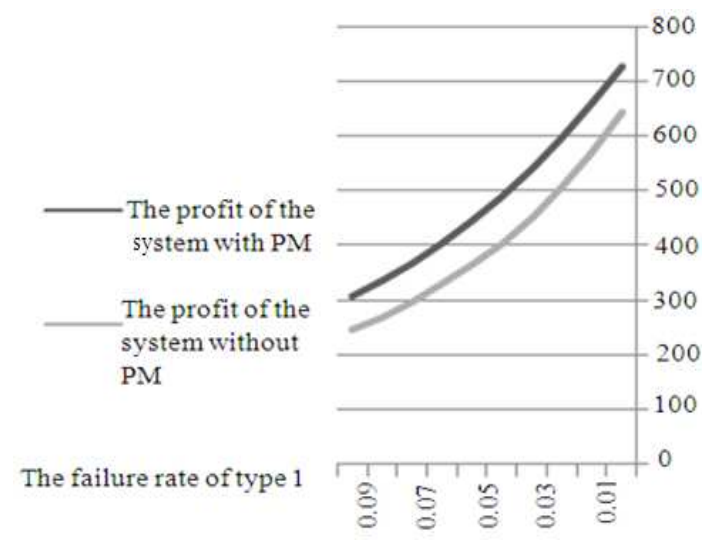

Fig. 4: Relation between the failure rate of type 1 and the expected total profit

\section{DISCUSSION}

By comparing the characteristic, MTSF, steady state availability and the profit function with respect to $\alpha_{1}$ for both systems with and without preventive maintenance graphically. It was observing that: The increase of failure rate $\alpha_{1}$ at constant $\alpha_{2}=0.04, \beta_{1}=0.05$, $\beta_{2}=0.06, \lambda=0.02, \delta=0.02, \quad \gamma=0.001, \quad \eta=0.04$, $\mathrm{R}=1000, \mathrm{C}_{1}=100, \mathrm{C}_{2}=50$, the MTSF, steady state availability and the profit function of the system was decreased for both systems with and without preventive maintenance.

Also graphs showed that: The system with preventive maintenance is greater than the system without preventive maintenance with respect to the MTSF, steady state availability and the profit function.

\section{CONCLUSION}

We conclude that: The system with preventive maintenance is better than the system without preventive maintenance with respect to the MTSF, steady state availability and the profit function.

\section{REFERENCES}

1. El-Saied, K.M., 2008. Cost analysis of a system with preventive maintenance by using the Kolmogorov's forward equations method. Am. J. Applied Sci., 5: 405-410. http://findarticles.com/p/articles/mi_7109/is_4_5/ai _n28552771/

2. Goel, L.R., G.C. Sharma and P. Gupta, 1986. Reliability analysis of a system with preventive maintenance inspection and two type of repair. Microelect. Reliab., 26: 429-433. http://cat.inist.fr/?aModele $=$ afficheN\&cpsidt=7912618

3. Gopalan, M.N. and H.E. Nagarwalia, 1985. Cost benefit analysis of a one server two-unit cold stand by system with repair and preventive maintenance. Microelect. Reliab., 25: 267-269. http://cat.inist.fr/?aModele=afficheN\&cpsidt=8407978

4. Goel, L.R., R. Gapta and S.K. Singh, 1985. Cost analysis of a two-unit cold standby system with two types of operation and repair. Microelect. Reliab., 25: 71-75. http://cat.inist.fr/?aModele=afficheN\&cpsidt=9254299

5. Said, E.L., M. Kh. and M.S. El-Sherbeny, 2005. Profit analysis of a two unit cold standby system with preventive maintenance and random change in units. J. Math. Stat., 1: 71-77. http://www.journaldatabase.org/articles/87074/Prof it_Analysis_of_A_Two_.html

6. Rander M.C., K. Suresh and K. Ashok, 1997. Cost analysis of two dissimilar cold standby system with preventive maintenance and replacement of standby. Microelect. Reliab. 34: 171.

7. Said, E.L., M. Kh. and M.S. EL-Sherbeny, 2005. Evaluation of reliability and availability characteristics of two different systems by using linear first order differential equations. J. Math. Stat., 1: 119-123.

http://www.journaldatabase.org/articles/90275/Eva luation_of_Reliability.html 